\title{
Implementation of New Irrigation Protocols on Strawberry Transplants on the California Central Coast
}

\author{
Stuart Styles ${ }^{1}$ and Kerilyn Ambrosini ${ }^{2}$ \\ ${ }^{1}$ Director, Irrigation Training and Research Center, BioResource and Ag \\ Engineering, Cal Poly State University, 1 Grand Avenue, San Luis Obispo, \\ California, 93407; PH (805)756-2434; FAX (805)756-2433; email: \\ sstyles@calpoly.edu \\ ${ }^{2}$ Engineering Technician, Irrigation Training and Research Center, BioResource and \\ Ag Engineering, Cal Poly State University, 1 Grand Avenue, San Luis Obispo, \\ California, 93407; PH (805)756-2434; FAX (805)756-2433; email: \\ kambrosi@calpoly.edu
}

\begin{abstract}
For the past five growing seasons, the Cal Poly Irrigation Training and Research Center (ITRC) has conducted research on water use, salinity levels and various other factors related to strawberry transplant establishment. This report summarizes research that can be found online: www.itrc.org/projects.htm.
\end{abstract}

The project's goal was to develop an analysis of irrigation practices of the strawberry growers on the central coast of California, primarily during the establishment of transplants. From the analysis, sprinkler use reduction methods were developed. These methods conserve water, save pumping costs, and reduce the runoff that can potentially contaminate local waterways. California growers contributed control and research plots to thoroughly represent the production areas and this project was a great success due to their input.

This project had a major impact on the strawberry industry and modified the methodology for irrigating a high value crop. This new methodology has been adopted by the innovative growers in California. After the developed irrigation methodology was in practice, growers reported up to a 15-percent yield increase, a 10-percent decrease in water usage and a peak production of strawberries earlier in the season. The key determinant in the transition to new irrigation management is the impact of salinity, which must be effectively managed.

\section{INTRODUCTION}

The California Polytechnic State University (Cal Poly) Irrigation Training \& Research Center (ITRC), in collaboration with academic, water district, and industry partners, implemented a multi-year study to evaluate new strategies for drip irrigation on strawberries to minimize water use during transplant establishment. This paper builds upon the paper entitled: "Strawberries: Effects of Modifying Irrigation Methods for Transplant Establishment", published in the World Environmental and Water Resources Congress 2011 (Styles, 2011). 
In the fall of 2008, the United Water Conservation District (UWCD) had a major flow rate capacity issue on the Pumping Trough Pipeline (PTP), which provides water to growers in the Oxnard, California area. The strawberry growers in the area transplanted their main season strawberry plants during the same period in October. When they transplanted their delicate strawberry plants, they applied water via sprinkler irrigation, for six to eight week durations after transplanting. This created a great water demand which exceed the capacity of the pipeline. Due to complaints of poor service, the UWCD decided to regulate sprinkler use in the month of October and even considered banning sprinkler irrigation in October. In response, local growers asked for assistance in finding the best solution to using less water, without a decrease in yield. At first, the most straightforward option was to eliminate the sprinklers and use the drip irrigation system that growers have installed previous to transplanting, but growers were still very concerned about salinity impacting the transplant health without the sprinkler leaching (Styles, 2011).

The project objectives were to keep the strawberry transplants healthy, while switching to drip irrigation as early in the season as possible. In the initial years of the project, the research and control plots were developed and the key factors in the early growth of transplanted strawberries. Once the key determinant of transplant health was found to be salinity, the relationships between irrigation water use and salinity level control were closely studied.

In general, salinity levels are reported in units of electrical conductivity (EC), for our report the units are deciSiemens per meter $(\mathrm{dS} / \mathrm{m})$. The three common EC

measurements are $\mathrm{EC}_{\mathrm{w}}$, salinity of the irrigation water, $\mathrm{EC}_{\mathrm{sw}}$, salinity of the soil water solution, and $\mathrm{EC}_{\mathrm{e}}$, salinity of the saturated soil extract. The $\mathrm{EC}_{\mathrm{sw}}$ is the salinity that the plants actually experience and the $\mathrm{EC}_{\mathrm{e}}$ of the same site is always lower than the $\mathrm{EC}_{\mathrm{sw}}$ due determination method (Burt and Styles 2007).

Strawberries have a very low tolerance of salinity in the soil and the irrigation water. According to Mass and Hoffman (1977), strawberry plants have an $\mathrm{EC}_{\mathrm{e}}$ threshold of $1.0 \mathrm{dS} / \mathrm{m}$ and a 33-percent yield decrease for every $1 \mathrm{dS} / \mathrm{m}$ increase in salinity. However, the threshold value is for $\mathrm{EC}_{\mathrm{e}}$, not $\mathrm{EC}_{\mathrm{sw}}$. The ITRC has found that $\mathrm{EC}_{\mathrm{sw}}$ values can exist up to $8 \mathrm{dS} / \mathrm{m}$ in some cases. Especially in a high value crop like strawberries, these salts needed to be leached out of the beds and this was the cause for the high water use during transplanting. Finding a balance between salinity levels and water use, without a yield decrease, was essentially the driving point of this study.

Throughout the project, the growers and field personnel were the driving force behind the success and conclusions drawn. The research protocol specified for the five-year period could not be strictly followed due to the growers adopting the new technology and methods. However, the growers' continuous contributions to the project allowed the ITRC to pinpoint issues and solutions, without extraneous data evaluation. 


\section{MATERIALS AND METHODS}

\section{DU Evaluations of Drip Irrigation Systems}

Distribution uniformity (DU) evaluations were performed on drip irrigation systems in fields in Watsonville, Santa Maria, and Oxnard. The goal was to analyze current irrigation strategies and offer suggestions to potentially conserve water and reduce energy costs for growers. A high distribution uniformity (greater than 0.85) is a good indicator that water is being supplied evenly across fields and few, if any, improvements are needed to the maintenance strategy or design of the irrigation system.

\section{Salinity Monitoring Sites}

Test Sites. This project consisted of blocks of strawberry plants in fields across the central coast of California. These test sites were selected to represent the areas of California where strawberries are commonly grown.

\section{Irrigation Methods to Evaluate}

The research evaluation identified three irrigation methods as test protocols:

- Sprinkler Irrigation Only (SIP) - sprinkler irrigation every day for up to six weeks, then switch to drip irrigation (this protocol is referred to as the "conventional" approach). The key issue with this protocol is the amount of runoff generated during transplant establishment. It is estimated that approximately 50 to 75-percent of the applied water will run off the field.

- Reduced Sprinkler Irrigation (RSI) - use sprinklers only for special cases for 3 to 8 irrigation events (e.g., right after transplanting, during hot dry wind events, frost protection), depending on extreme weather conditions such as the Santa Ana wind events

- Drip Irrigation Only (DIO) - drip irrigation every day for the entire season

\section{Santa Ana Wind Events}

The "Santa Anas" are winds in Southern California that have speeds over 25 knots (46 kph) and can range to over twice that speed. Data for the events are monitored by the National Oceanic and Atmospheric Administration (NOAA). Santa Ana-type conditions are usually associated with hot, low humidity (around 10-20-percent). Figure 1 illustrates direction of air flow over the Sierra Nevada Mountains through the San Gabriel and San Bernardino Mountains (Tyree, 2012).

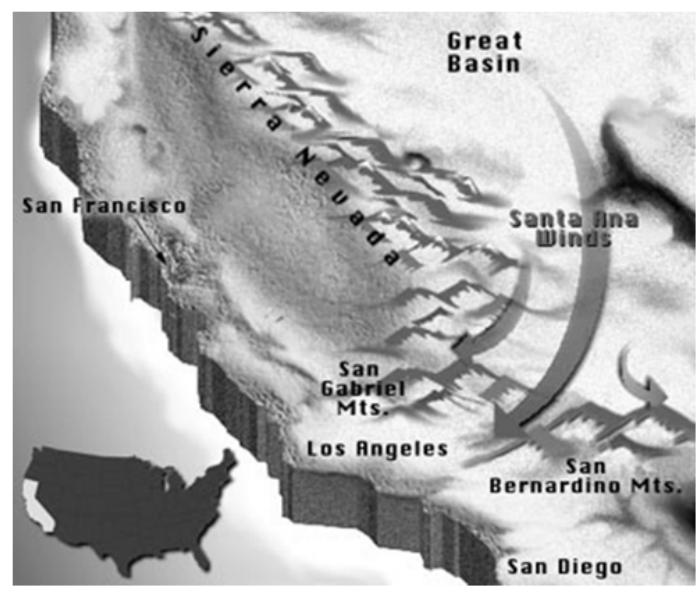


Figure 1. Diagram showing movement of Santa Ana winds from the Great Basin, down the Sierra Nevada Mountains into California (Tyree, 2012)

When the Great Basin is much cooler than the Los Angeles Basin, typically from October to March, high pressure can build in the Great Basin. Around a high pressure system in the Northern Hemisphere, air flows clockwise. This causes the wind to flow from the Great Basin into the Los Angeles Basin, from the northeast and the east to the coast of California. Since the Great Basin is at a higher elevation than the Los Angeles Basin, when the air flows downward to the Los Angeles Basin it is heated adiabatically. In other words, when the air mass descends it is compressed and, therefore heated up at a rate of almost 272 Kelvin per mile. When the air temperature rises, the relative humidity, in turn, decreases. This essentially creates "thirsty" air that will suck moisture from everything, including vegetation. The Santa Ana wind events happen at a crucial time for strawberry crops, the transplant stage. Extra attention must be paid to water application when these winds are blowing as they can take a large amount of moisture out of the plants and cause detrimental damage.

\section{Data Collection}

For the data collection of the project, ITRC technician visited each site and downloaded the data for evaluation. The data collected consisted of:

- Decagon Data Loggers: salinity (EC in $\mathrm{dS} / \mathrm{m}$ ), volumetric water content of the soil (\%VMC), and temperature (degrees $\mathrm{F})$, measured in 15-minute intervals

- Volumetric water applied to field block (acre-feet)

- Soil salinity shallow analysis (EC in $\mathrm{dS} / \mathrm{m})$,

- Irrigation water salinity sampling (EC in $\mathrm{dS} / \mathrm{m})$

- Soil sampling (monthly)

- Soil salinity root zone contours (EC in $\mathrm{dS} / \mathrm{m}$ ).

During the transplanting period, weekly visits were conducted. The frequency of data collection allowed the analysis and feedback relating to the soil salinity levels during the most sensitive and crucial plant growth period. Towards the middle and end of the season, bi-weekly data collection was conducted, as the plants are have a much higher resistance and tolerance to salinity during this period. In general, the Decagon Em50 Data Loggers were robust and required minimal maintenance. However, since the units are battery operated, batteries would need replacing and occasionally as 5TE sensor would fail.

\section{Data Loggers}

Decagon Em50 Data Loggers were installed at every site at the Oxnard, Santa Maria and Watsonville locations. These small data loggers were placed as close to the center of the block as possible. Their compact size allowed them to be placed virtually anywhere in the field without the risk of damage from passing equipment. Each data logger was connected to two Decagon 5TE soil moisture/temperature/EC sensors and one Decagon PS1 pressure switch. The 5TE sensors were run down the strawberry bed and placed at a depth of $7.6 \mathrm{~cm}$ in the middle plant row. To monitor moisture, salinity and water movement in the root zone, additional 5TE sensors were 
installed at depths of 15.2 and $30.5 \mathrm{~cm}$. The PS1 pressure switch was connected using a brass $\mathrm{T}$ connection to a nearby sprinkler head, in order to monitor the duration and frequency of sprinkler irrigations.

\section{Soil Sample Procedure}

To further investigate particular salt concentrations in the soil, monthly soil samples were collected on each. Samples were selected from 0-7.6 cm, 7.6-15.2 cm, and $15.2-30.4 \mathrm{~cm}$ from the two middle plant rows, near the data logger location in the field. For precision verification, a handheld Decagon ProCheck with a 5TE sensor was used to record salinity and soil moisture content at each of the three depths. The samples were taken from near the center of the field close to where the 5TE data logger sensors were located. Each soil sample was taken from the same relative section of the text block.

\section{Salinity 5TE Shallow Analysis}

In an attempt to track the movement of salts, EC measurements were taken across the top of the strawberry bed at a depth of $7.6 \mathrm{~cm}$ on numerous occasions throughout the growing season. This was done using a handheld Decagon ProCheck device with a 5TE sensor. Measurements were taken at the nine locations on the sides and on top of the bed. These measurements were taken near the middle bed at both ends of each block. The locations of the measurements vary somewhat between dates, but for a given date, each measurement was taken from the same spot in each field.

\section{Water Sample Procedure}

Water samples were taken whenever water was on the site. This gave some idea as to the quality of the irrigation water that was being used at each site. A waterproof total dissolved solids tester was used to test samples.

\section{Photo Log Procedure}

Pictures were taken of each test site during each visit. This allowed the growth process of strawberries at each site to be monitored and later compared. All pictures were taken facing north from the location of the data logger in each field. One of the best methods to determine the health of the transplants during establishment has been the evaluation of the photos.

\section{RESULTS}

Distribution Uniformity Evaluations. The desired DU value for all of the fields was 0.85 , which is the statewide average for all drip irrigation systems. The results from the DU evaluations are presented in Table 1. Proper design and maintenance are important in order to maximize distribution uniformity over the entire growing season. This may include:

- Installing pressure regulators at the head of each manifold, or adjusting regulators to the correct setting

- Adequately backflushing filters

- Routinely flushing hoses and repairing leaks 
Table 1. Distribution uniformity results of fields along the Central Coast.

\begin{tabular}{|l|l|l|}
\hline \multicolumn{1}{|c|}{ Farm } & \multicolumn{1}{c|}{ Location } & \multicolumn{1}{c|}{ System DU } \\
\hline Manzanita 2 & Santa Maria & 0.84 \\
\hline Manzanita 7 & Santa Maria & 0.86 \\
\hline Gamble Ranch & Santa Maria & 0.80 \\
\hline Los Padres Berry Farm & Santa Maria & 0.90 \\
\hline Sammis & Oxnard & 0.67 \\
\hline Eclipse Berry Farm (1) & Oxnard & 0.73 \\
\hline Eclipse Berry Farm (2) & Oxnard & 0.74 \\
\hline Peikert Ranch & Oxnard & 0.76 \\
\hline Corey Ranch & Watsonville & 0.87 \\
\hline
\end{tabular}

The DU evaluations were repeated each year. There was a noticeable difference in DU scores over the last two seasons due to the time in the season the evaluation was performed and increased grower awareness of uniformity problems. Growers have started to place more emphasis on maintaining a consistent pressure distribution over the entire field. There is also a substantial difference in the drip system's performance over the length of the growing season.

\section{Soil Salinity Continuous Data}

All continuous data was obtained from the Decagon data loggers. The resulting data was highly variable between all of the test plots. This made a statistical analysis of the salinity data infeasible. Clearly there is a tremendous amount of uncertainty associated with managing salinity. Additionally, the charts clearly show the huge effect that rainfall has on salinity. The data showed that a heavy rain in January lowered salinity levels by up to 50-percent while sprinkler irrigation events had much less impact on the soil salinity. This was primarily due to the fact that the rainwater has a low $\mathrm{pH}$ value and no salt content.

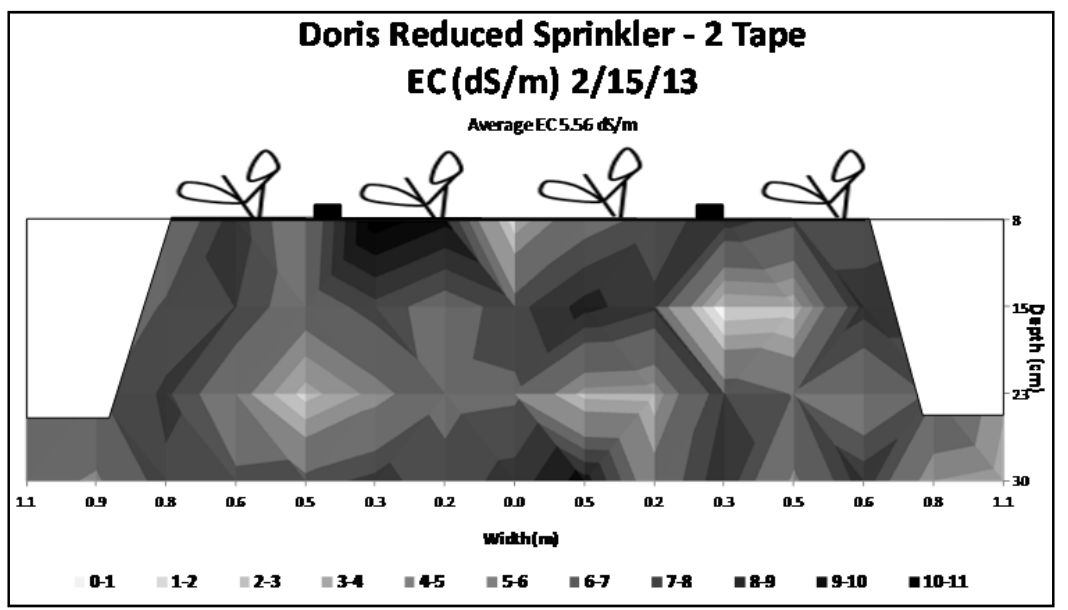

Figure 2. Salinity contour graph $(\mathrm{dS} / \mathrm{m})$ at Doris site

From the soil salinity data collected, salinity contours graphs were made (shown Figure 2). The graphs display values of salinity $(\mathrm{dS} / \mathrm{m})$ in the plant beds. These are useful to the grower for analyzing where the salt is pushed by applied water. The 
darkest grey color signifies EC values of $10 \mathrm{dS} / \mathrm{m}$ or higher, which is considered toxic to the plant if not leached.

\section{Rainfall and Salinity data}

The data from the sensors was easily uploaded to a spreadsheet. This spreadsheet contained data from the entire study, displaying salinity levels in both water and soil. It also contained precipitation data, as well as number of minutes the sprinklers were running. All of the data was collected from the fields except for the precipitation data. The precipitation data was obtained from California Irrigation Management Information System (CIMIS, 2013) or the Weather Underground (Weather Underground, 2013) websites using the nearest airports as the location. After all of the data was uploaded into the spreadsheet, graphs were made to visually monitor the salinity levels.

It was found that the salinity values fluctuated daily and that the salinity dropped after a rainfall event, which indicates localized leaching close to the sensors. After the rain event, the salinity values increased again. This was only true for the sensors only in the $0-7.6 \mathrm{~cm}$ range. No trending with rainfall was observed in the $7.6-30.2 \mathrm{~cm}$ range, which indicated minimal downward movement of the applied water.

\section{Water Use Data}

Throughout the season, the water use at the sites was monitored by periodic meter readings. The trends could be viewed over several seasons. The total water was found to be around the same each year. The total water seemed to decrease over the span of the study, but it must be noted that the amount of total water is also dependent on weather conditions, which vary by year.

\section{Nitrogen Application Method Change}

One unintended, yet positive, impact of this project was the shift in nitrogen application methods. Before the study, growers applied up to 80-percent of their nitrogen before transplanting and the other 20-percent during the season through the irrigation system. Our results showed that this historic method contributed to the salinity levels and, in turn, the yields. Some of the growers have now shifted their strategy by apply only 20-percent of their nitrogen before transplanting and 80 percent during the season. Results also helped show growers how gypsum and other additives (like composting) can raise soil salinity.

\section{Impact on Yields}

In first two seasons, yields did not seem to vary with irrigation method. However, in the first season there was noticeable damage to plants where the salinity levels were very high due to the placement of the drip irrigation tape. The conclusion was that even though there was some die-off, the other plants seemed to respond better, which kept the yields about equal to previous years. The other conclusion was that the placement of the drip tape was important (Styles, 2011). 
The data from Sammis in the second year also indicated that the yields improved using the new irrigation methods. The reduced sprinkler protocol had an 8-percent increase in yield and the drip only protocol had a 13-percent increase in yield.

The third season yields were higher with the new irrigation protocol. The yield increase in Manzanita was 13-percent on the reduced sprinkler protocol compared to the conventional protocol. The grower also reported the yields on the reduced sprinkler protocol resulted in early field gains at a time when the market prices were favorable.

The fourth year of data saw a dramatic drop-off in the data collection of yields by the early innovators. These growers switched their whole fields over to the new protocol and abandoned the "conventional" irrigation approach, with the exception of the Sammis site.

The fifth year yields grew at a fast rate, but then declined rapidly earlier in the season than in previous years. Figure 3 shows a side-by-side comparison of yields over the five growing seasons of the study for Sammis using the reduced sprinkler method.

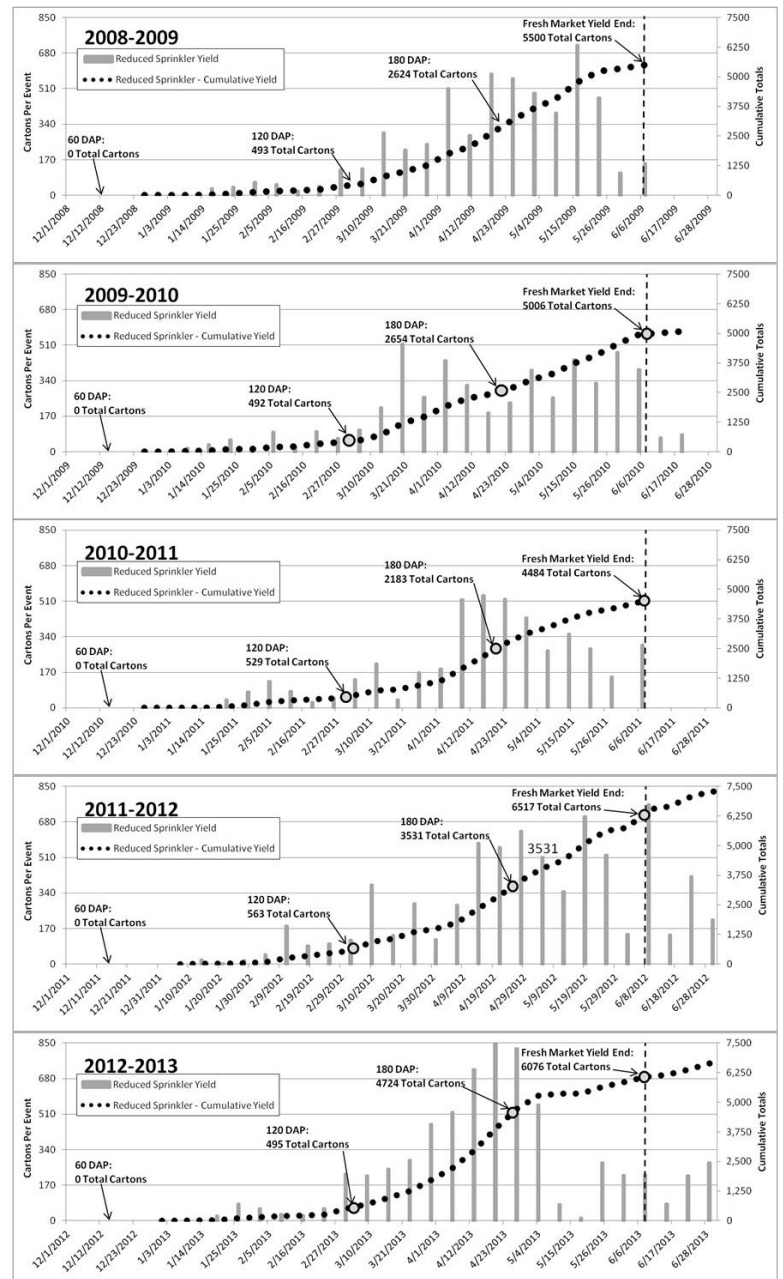

Figure 3. Five years of yield data from Sammis RSI block 
Preliminary conclusions can be drawn from the graphs used in the evaluation (examples shown in Figure 3):

- Annual water use tends to remain consistent between growing seasons, with the exception of Sammis during the fourth growing season.

- Yields fluctuate on a year-to-year basis based on numerous factors. The overall weather seems to be a major determinant on yields. Rainfall was less abundant during the first year of the project. The third year had three times more rainfall than the first. The hotter, dryer weather may have led to better yields in the first year. Keep in mind that the first year on the drip only saw a 30-percent die-off due to salinity damage.

\section{DISCUSSION}

The results from the first and second year were mixed due to some major die-off issues (up to 30-percent in one demonstration plot). The first year seemed to be dominated by low rainfall and numerous Santa Ana wind events. While generally unsuccessful in terms of results, the grower wanted to continue the study since the potential seemed promising, and there were numerous key lessons learned.

The third year showed increases in yield and decreases in water use. There were decreases in water use of up to 10-percent and a surprising increase in yields was reported.

The fourth year focus shifted to a more detailed analysis considering tape layouts and salinity location. The key conclusions at the end of the fourth year were:

- Salinity is a key determinant in the healthy establishment of the strawberry transplants. The young plants will not tolerate high levels of salts. The damage in the plants will appear similar to a plant that lacks sufficient water.

- Row crop drip tape must be placed correctly in order to micro-leach salts in the beds. This means that in the Oxnard Plain, growers may need to use four low flow tapes in order to successfully switch to the drip only or reduced sprinkler protocols. Growers in Santa Maria might be able to use only two tapes per bed (on lighter soils) but the salinity must be evaluated in order to make sure the salts are not building up at the base of the plant. Using three tapes is not recommended on beds with four plant rows. However, it is being done on a number of ranches.

- Monitoring the salinity of the soil and the irrigation water will help growers switch from the conventional irrigation method to a new protocol. The soil salinity should be less than $7 \mathrm{dS} / \mathrm{m}\left(\mathrm{EC}_{\mathrm{e}}\right)$ and the water salinity should be less

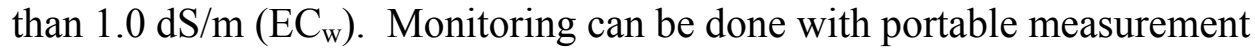
equipment but should be verified using professional soil labs.

- The irrigation water is one of the key determinants of whether there may be a problem. If the water quality is $1.0 \mathrm{dS} / \mathrm{m}$ or less, the impact is minimal. If the salinity of the irrigation supply water is $1.2 \mathrm{dS} / \mathrm{m}$, the grower could see a 10 to 25-percent yield impact. It should be noted that well water, surface water, and 
reclaimed water sources have changing salinity characteristics during the season.

- Salts come from various sources. Some sources of salt include the irrigation water, gypsum applications, fertilizers (both pre-plant and liquid), and composting (which can be a significant source).

- Traditional salinity references have used soil salinity as the key determinant for the salt impact on yields. The traditional approach states that if the soil salinity $\left(\mathrm{EC}_{\mathrm{e}}\right)$ approaches $4.0 \mathrm{dS} / \mathrm{m}$ the yield will be 100 -percent impacted (i.e., no yield). However, this research confirmed most growers in the Oxnard Plain routinely work in soils at 4-6 dS/m with very little impact on yields. The reason is that they have been managing their salts properly near the roots of the young plants.

- Soils that are lighter will be easier to irrigate and manage than soils that are heavy. This has been observed in the various plots as part of this research.

- Rain washes salts away from young strawberry transplants. The data clearly show that rainwater (which is essentially salt-free and acidic) can push harmful salts away from the plants. The data show how dramatically the salinity level dropped after the rain.

- The new protocols result in a yield increase up to 10-percent. The new protocols have also decreased the water use by over 10-15-percent. This research project has shown that the new approach has resulted in more crops per drop.

The fifth year shifted focus to distribution uniformities. Of the nine evaluated sites, the average distribution uniformity is 0.80 . This is below the statewide average due to pressure variability seen across some of the evaluated strawberry fields. Overall, results seemed promising with higher uniformities than previous years.

After five years of evaluation and testing, the most commonly used method for irrigating strawberries in California is the Reduced Sprinkler Irrigation methodology developed by this study. Growers use sprinklers for bed preparation and salinity control, then eventually switch to drip after transplanting. They continue to use sprinkler irrigation as an insurance policy to prevent plant and soil bonding, clean off the leaves, control salinity, and prevent frost damage, even though field observations have shown that only a small portion of the water applied by sprinklers actually infiltrates through the plastic mulch to the deeper plant roots.

The California strawberry industry redeveloped their methods due to the findings of this project. The growers are the reason for this great progress. The ITRC supplied the resources and evaluations to help the growers improve their irrigation practices. 


\section{REFERENCES}

Bernstein, L. (1965 (rev. 1980)). Salt tolerance of fruit crops. U.S. Dept. Agric. Info. Bull. No. 292. U.S. Government Printing Office, Washington, D.C. p 8.

Burt, C. M. and S.W. Styles. (2007). Drip and Micro Irrigation Design and Management for Tree, Vines, and Field Crops. $3^{\text {rd }}$ ed. Irrigation Training and Research Center. San Luis Obispo, CA.

CIMIS. (2013). Daily CIMIS Data. California Irrigation Management Information System. Department of Water Resources, Office of Water Use Efficiency. Online at: $<\underline{\text { http://wwwcimis.water.ca.gov/cimis/data.jsp }>}$

Ehlig, C.F., and L. Bernstein, (1958). Salt tolerance of strawberries. In: Proc. Amer. Soc. Hort. Sci. 72 (1958), pp. 198-206.

Krist, J. (2007). Nitrates Seep into Aquifers. Ventura County Star. June 24.

Larson, K.D. (1994). Strawberry. In: B. Schaffer and P.C. Anderson (eds.). Handbook of environmental physiology of fruit crops. vol. 1. Temperate crops. CRC Press, Boca Raton, Fla. pp 271-297.

Maas, E.V. (1990). Crop salt tolerance. In Agric. Salinity Assessment and Management. Ed. K.K. Tanji. Amer. Sot. Civil Eng. Manuals and Reports on Engineering No. 7 1, ASCE, New York, pp 262-304.

Maas, E.V. and G.J. Hoffman. (1977). Crop salt tolerance-current assessment. J. Irrig. Drain. Div., ASCE 103(IR2): 115-134.

Styles, S., L. Groundwater, and C. Lutje. (2011). "Strawberries: Effects of Modifying Irrigation Methods for Transplant Establishment". Proc. World Environmental and Water Resources Congress 2011, ASCE, 2729-2739.

Suarez, D.L. and C.M. Grieve. (2007). Response of strawberry cvs. Ventana and Camarosa to salinity and specific ion composition of irrigation water. Meeting Abstract. In: Proceedings of the 2007 North American Strawberry Symposium, held in Ventura Beach, CA. February 9-12, 2007. pp 171-172.

Tyree, Mary K. (2012). Santa Ana. California Nevada Applications Program / California Climate Change Center Website.

Weather Underground. (2013). Weather History for Santa Maria, CA. $<$ http://www.wunderground.com/history/airport/KSMX/2013/7/31/DailyHistory.html $>$ 